\title{
The Transient versus the Equilibrium Response of Sea Ice to Global Warming
}

\author{
CHAO LI \\ Max Planck Institute for Meteorology, and International Max Planck Research School on Earth System Modelling, \\ Hamburg, Germany \\ DIRK NOTZ \\ Max Planck Institute for Meteorology, Hamburg, Germany \\ STEFFEN TIETSCHE \\ Max Planck Institute for Meteorology, and International Max Planck Research School on Earth System Modelling, \\ Hamburg, Germany \\ JOCHEM MAROTZKE \\ Max Planck Institute for Meteorology, Hamburg, Germany
}

(Manuscript received 26 July 2012, in final form 23 January 2013)

\begin{abstract}
To examine the long-term stability of Arctic and Antarctic sea ice, idealized simulations are carried out with the climate model ECHAM5/Max Planck Institute Ocean Model (MPI-OM). Atmospheric $\mathrm{CO}_{2}$ concentration is increased over 2000 years from preindustrial levels to quadrupling, is then kept constant for 5940 years, is afterward decreased over 2000 years to preindustrial levels, and is finally kept constant for 3940 years.

Despite these very slow changes, the sea ice response significantly lags behind the $\mathrm{CO}_{2}$ concentration change. This lag, which is caused by the ocean's thermal inertia, implies that the sea ice equilibrium response to increasing $\mathrm{CO}_{2}$ concentration is substantially underestimated by transient simulations. The sea ice response to $\mathrm{CO}_{2}$ concentration change is not truly hysteretic and is in principle reversible.

The authors find no lag in the evolution of Arctic sea ice relative to changes in annual-mean Northern Hemisphere surface temperature. The summer sea ice cover changes linearly with respect to both $\mathrm{CO}_{2}$ concentration and temperature, while the Arctic winter sea ice cover shows a rapid transition to a very low sea ice coverage. This rapid transition of winter sea ice is associated with a sharply enhanced ice-albedo feedback and a sudden onset of convective-cloud feedback in the Arctic.

The Antarctic sea ice cover retreats continuously without any rapid transition during the warming. Compared to Arctic sea ice, Antarctic sea ice shows a much more strongly lagged response to changes in $\mathrm{CO}_{2}$ concentration. It even lags behind the surface temperature change, which is caused by a different response of ocean deep convection during the warming and the cooling periods.
\end{abstract}

\section{Introduction}

Simple models suggest that sea ice might exhibit multiple equilibria as a result of the ice-albedo feedback (e.g., Budyko 1969; Sellers 1969; North 1990). A possible irreversible shift of the sea ice state caused by anthropogenic climate change is of particular concern in evaluating the

Corresponding author address: Chao Li, Max Planck Institute for Meteorology, Bundesstrasse 53, 20146 Hamburg, Germany.

E-mail: chao.li@zmaw.de potential societal and environmental threat posed by future climate change, especially given the strong retreat of Arctic summer sea ice that has been observed in recent decades (e.g., Vinnikov et al. 1999; Lindsay and Zhang 2005; Stroeve et al. 2012). The present study explores the long-term stability and the possibility of hysteresis behavior of Arctic and Antarctic sea ice by performing long-term integrations with a state-of-the-art coupled atmosphereocean-sea ice general circulation model (AOGCM).

If the climate is altered, a transition may occur between climate states that is not reversible by returning 
the climate to its previous regime (this irreversibility is termed "hysteresis behavior"). Recently, Armour et al. (2011) and Ridley et al. (2012) investigated the reversibility of sea ice retreat in AOGCM integrations with "ramp up and ramp down" atmospheric $\mathrm{CO}_{2}$ concentration. Both studies found no evidence of irreversible behavior of sea ice in the Arctic Ocean and the Southern Ocean in a future warm climate.

Here we extend these previous studies in a variety of ways. We put greater emphasis on the long-term evolution of the climate system and on the difference between the transient and the equilibrium response of sea ice. The sea ice-covered states in Armour et al. (2011) and Ridley et al. (2012) are still transient because in these studies atmospheric $\mathrm{CO}_{2}$ concentration was changed too quickly to result in a quasi-equilibrium system. $\mathrm{CO}_{2}$ was increased by $1 \% \mathrm{yr}^{-1}$ in Armour et al. (2011) and by $2 \% \mathrm{yr}^{-1}$ in Ridley et al. (2012). In addition, these experiments were not run long enough to allow the deep ocean to reach equilibrium. Ridley et al. (2008) found that Arctic sea ice had not reached equilibrium even after 600 years of stabilization following an atmospheric $\mathrm{CO}_{2}$ quadrupling. Recently, Li et al. (2013) found that the deep-ocean temperature change following atmospheric $\mathrm{CO}_{2}$ quadrupling is fully equilibrated only after about 5000 years. They also found that long-term deep-ocean adjustments play an important role in determining the surface equilibrium temperature change, in particular in high latitudes. Such slow oceanic adjustments might exhibit hysteretic behavior and, in turn, might render the sea ice loss irreversible. The slow oceanic adjustments could also cause differences between increasing and decreasing surface temperature trajectories (Stouffer 2004) and thereby cause a lagged response of sea ice.

In the present study, we examine the possible hysteresis behavior of sea ice in response to changes in atmospheric $\mathrm{CO}_{2}$ forcing using our state-of-the-art AOGCM ECHAM5/Max Planck Institute Ocean Model (MPI-OM). In contrast to the experiments of Armour et al. (2011) and Ridley et al. (2012), we perform experiments in which both the increase and the decrease of the atmospheric $\mathrm{CO}_{2}$ forcing occur very slowly over 2000 years, hoping to ensure a quasi-equilibrium system. In addition, four experiments are carried out in which the $\mathrm{CO}_{2}$ concentration is kept constant at intermediate levels until the climate has reached equilibrium. Such experiments are necessary to clarify whether indeed the warming and the cooling trajectories change the $\mathrm{CO}_{2}$ concentration slowly enough to maintain quasi equilibrium. In addition, the experiments with constant forcing allow us to determine whether the sea ice response shows true hysteretic behavior. Such behavior is only found if (i) the system shows a different response to a certain forcing for the increasing and the decreasing trajectory of the forcing, and (ii) if such multiple states for the same external forcing are stable if the forcing is kept constant for a very long time at these levels. Because of these requirements, the determination of true hysteretic behavior is computationally very expensive in an AOGCM.

Since we vary the $\mathrm{CO}_{2}$ concentration very slowly, the trajectories of the model's response are closer to quasi equilibrium than those of previous studies. Hence, our experimental design is well suited to examine if and why for very slowly varying forcing the transition between two sea ice states can be rapid. Addressing this question in a single-column model, Eisenman and Wettlaufer (2009) found a smooth transition from a perennially icecovered state to a seasonally ice-free state during a gradual increase in forcing, and a sudden loss of the remaining winter sea ice for further increased forcing. Since the large-scale processes are highly parameterized in such conceptual models, the transition scenarios of the sea ice strongly depend on the choice of the parameterizations [as reviewed by Eisenman (2012)]. But the transition of sea ice is also model dependent in AOGCMs. For example, in comparing phase 3 of the Coupled Model Intercomparison Project (CMIP3) model output, Winton (2006) found that for $\mathrm{CO}_{2}$ quadrupling, the Community Climate System Model, version 3.0 (CCSM3.0), shows a linear loss of Artic winter sea ice, while ECHAM5/ MPI-OM shows a rapid collapse of winter sea ice once a certain temperature threshold has been exceeded. A similar behavior of a rapid decrease in Arctic winter sea ice cover was also found in the phase 5 of the CMIP (CMIP5) representative concentration pathway 8.5 (RCP8.5) scenario simulations with ECHAM5/MPI-OM's successor, the Max Planck Institute Earth System Model (MPIESM; Notz et al. 2013). The different response of winter sea ice in ECHAM5/MPI-OM compared to CCSM3.0 implies that also the reversibility of sea ice could be different between the two models. Since Armour et al. (2011) used CCSM3.0 and we use ECHAM5/MPI-OM, we can directly address this point.

In addition to a possible nonlinear response of winter sea ice, we also examine a possible nonlinear response of summer sea ice to a slow change in forcing. Using the twenty-first century climate projections from the CMIP3 model runs, several studies have indicated that the complete loss of Arctic summer sea ice would occur in a continuous fashion (e.g., Winton 2006, 2008; Ridley et al. 2008). Confirming such a linear response, Tietsche et al. (2011) found that the summer sea ice extent recovered within about 2 years when they removed all of the Arctic sea ice at various times during a simulation of twenty-first century climate with ECHAM5/MPI-OM (the same model is used in the present study). Some 
AOGCMs do exhibit abrupt reductions in summer minimum Arctic sea ice cover (Holland et al. 2006); however, these are a consequence of increased interannual variability of sea ice extent due to the slow shift in icethickness distribution (Holland et al. 2008; Notz 2009).

The remainder of the paper is organized as follows: in section 2, we give a brief introduction of the model and experimental design. Section 3 shows the changes in surface temperature in response to changes in atmospheric $\mathrm{CO}_{2}$ concentration. In section 4 , we investigate the possibility of hysteresis in Arctic sea ice, section 5 discusses the possibility of hysteresis in Antarctic sea ice, and we close the paper in section 6 with our conclusions.

\section{Model and experimental design}

The AOGCM applied in this study is a coarse-resolution version of ECHAM5/MPI-OM. The spectral atmospheric model ECHAM5 is run at T31 resolution $\left(\sim 3.75^{\circ}\right)$ with 19 levels (Roeckner et al. 2003, 2006). The MPI-OM is used with a curvilinear grid that has a horizontal resolution of roughly $3^{\circ}$ near the equator and a horizontal resolution of $50-200 \mathrm{~km}$ in the Arctic Ocean, with 40 vertical levels. Details of MPI-OM and the embedded sea ice model can be found in Marsland et al. (2003) and Jungclaus et al. (2006). The embedded sea ice model is a dynamic-thermodynamic sea ice model with viscousplastic rheology and snow (Hibler 1979). Thermodynamic growth of sea ice is described by the zero-layer formulation of Semtner (1976). Ocean and atmosphere are coupled daily using the Ocean Atmosphere Sea Ice Soil, version 3.0 (OASIS3.0), coupler (Valcke et al. 2003). The same model setup has been used to investigate the longterm adjustment of deep-ocean heat uptake and equilibrium climate response to atmospheric $\mathrm{CO}_{2}$ forcing $(\mathrm{Li}$ et al. 2013). A higher-resolution version of the model (Jungclaus et al. 2006) has been used for the scenario simulations assessed in the Intergovernmental Panel on Climate Change (IPCC) Fourth Assessment Report (AR4).

We use this model to perform the following experiments: the first integration is a 1600 -year-long preindustrial control run (CNTR) with a constant atmospheric $\mathrm{CO}_{2}$ concentration of 278 ppmv. CNTR is close to a steadystate climate at the end of the simulation. The last 100 years are used as the CNTR reference in this study. A second integration starts from the end of CNTR; the atmospheric $\mathrm{CO}_{2}$ concentration is linearly increased from its preindustrial level to quadrupling over 2000 years (CO2_UP in Fig. 1a), and is held constant thereafter for a further 5940 years until the whole system has reached equilibrium (CO2_HIGH in Fig. 1a). A third integration starts from the end of $\mathrm{CO} 2$ HIGH; the atmospheric $\mathrm{CO}_{2}$ concentration is linearly decreased from quadrupling to its preindustrial level over 2000 years (CO2_DOWN in Fig. 1a), and is held constant thereafter for further 3940 years until the whole system has reached equilibrium (CO2_LOW in Fig. 1a). We change the atmospheric $\mathrm{CO}_{2}$ concentration very slowly, hoping to keep the system close to a quasi equilibrium. To examine whether the quasi equilibrium is really maintained, four additional simulations with a constant atmospheric $\mathrm{CO}_{2}$ concentration at 490 and 780 ppmv are carried out for 2500 years during both CO2_UP and CO2_DOWN (A, B, C, and D in Fig. 1a). Overall, almost 24000 years of simulations are completed in this study.

In this study, we performed idealized experiments with prescribed atmospheric $\mathrm{CO}_{2}$ concentrations that are kept constant over long periods of time. The long-term change of the atmospheric $\mathrm{CO}_{2}$ concentration due the carbon cycle processes in the earth system has not been included. Moreover, the coupled climate model used here has neither dynamic glaciers nor dynamic vegetation; as one consequence, we cannot explore the impact of ice sheet melting on the sea ice change. Our idealized experimental strategy allows us, however, to explore the true equilibrium response of a climate model to atmospheric $\mathrm{CO}_{2}$ concentration change.

\section{Response of the surface temperature to atmospheric $\mathrm{CO}_{2}$ forcing}

As the atmospheric $\mathrm{CO}_{2}$ concentration increases in CO2_UP, the global-mean surface temperature continuously increases, resulting in a total warming of $9.9 \mathrm{~K}$ (Fig. 1b). The Northern Hemisphere (NH) mean surface temperature increases by $10.2 \mathrm{~K}$, and the Southern Hemisphere ( $\mathrm{SH}$ ) mean surface temperature increases by $9.6 \mathrm{~K}$. The mean surface temperature is almost stationary while keeping $\mathrm{CO}_{2}$ concentration fixed at $1112 \mathrm{ppmv}$ in $\mathrm{CO} 2$ HIGH. As the atmospheric $\mathrm{CO}_{2}$ concentration decreases in CO2_DOWN, the global-mean and hemispheremean surface temperature decrease again. However, for the same amount of the atmospheric $\mathrm{CO}_{2}$ concentration the cooling trajectory has much higher temperatures than the warming trajectory (Fig. 2). As the atmospheric $\mathrm{CO}_{2}$ concentration reaches its preindustrial level in CO2_DOWN, the global-mean surface temperature is $3.3 \mathrm{~K}$ warmer than that in CNTR. After keeping the $\mathrm{CO}_{2}$ concentration at the preindustrial for several millennia (CO2_LOW), the global-mean and hemispheric-mean temperatures eventually return to their preindustrial state. Such convergence of the temperature for $\mathrm{CO} 2$ _UP and $\mathrm{CO} 2$ _DOWN also occurs at intermediate $\mathrm{CO}_{2}$ concentration: keeping the atmospheric $\mathrm{CO}_{2}$ concentration fixed at 490 and 780 ppmv for 2500 years each, the surface 


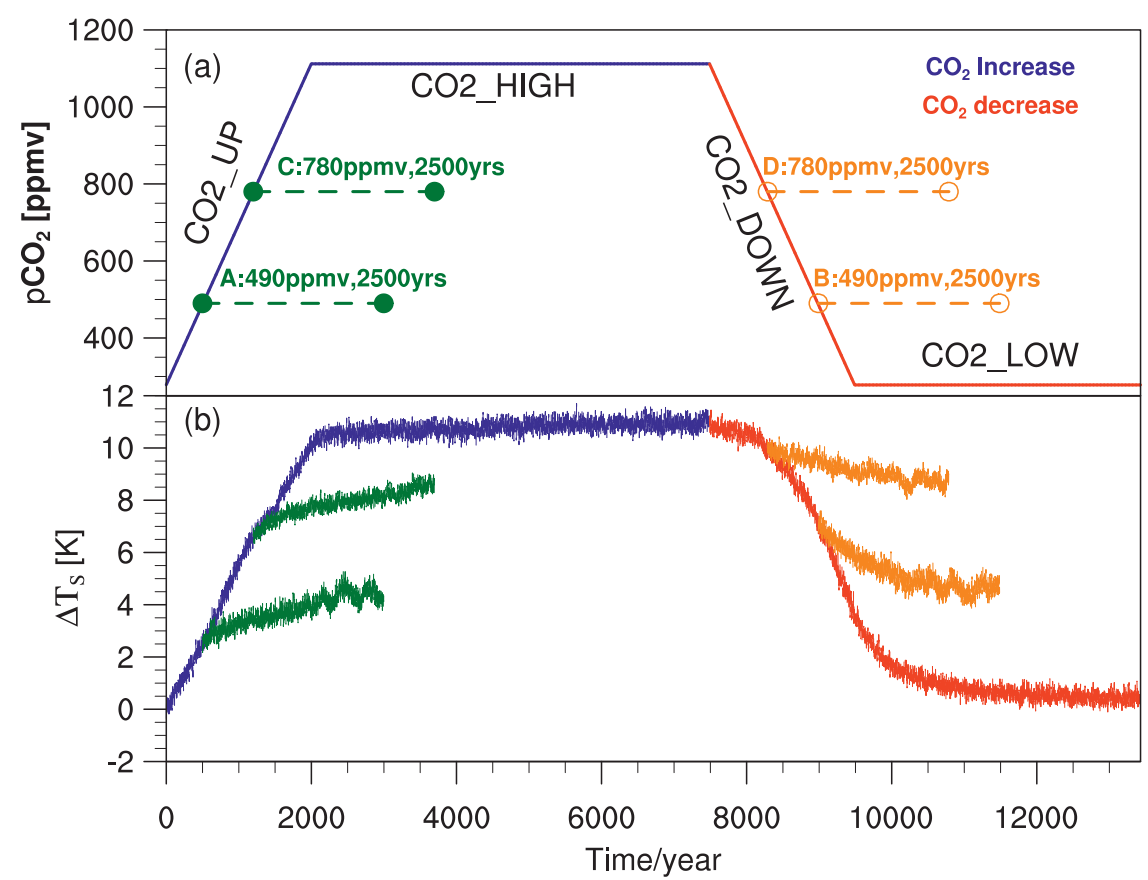

FIG. 1. Time series of (a) the prescribed atmospheric $\mathrm{CO}_{2}$ concentration and (b) global annualmean surface temperature change. Increasing $\mathrm{CO}_{2}$ concentration (blue) results in a warming trajectory and decreasing $\mathrm{CO}_{2}$ concentration (red) results in a cooling trajectory. $\mathrm{CO} 2$ _UP is the period when the $\mathrm{CO}_{2}$ concentration is increased from 278 to 1112 ppmv over 2000 years; CO2_HIGH is the period when the $\mathrm{CO}_{2}$ concentration is stabilized at 1112 ppmv over 5940 years; CO2_DOWN is the period when the $\mathrm{CO}_{2}$ concentration is decreased from 1112 to 278 ppmv over 2000 years; and CO2_LOW is the period when the $\mathrm{CO}_{2}$ concentration is stabilized at 278 ppmv over 3940 years. The dark green experiments start from the $\mathrm{CO} 2$ _UP with $\mathrm{CO}_{2}$ concentration fixed at 490 and 780 ppmv for 2500 years. The dark orange experiments start from CO2_DOWN with $\mathrm{CO}_{2}$ concentration fixed at 490 and 780 ppmv for 2500 years. Temperature anomalies are with respect to the CNTR.

temperature of the cooling trajectory and the surface temperature of the warming trajectory slowly approach each other (Figs. 2a-c). Hence, the offset between the cooling trajectory and the warming trajectory simply implies a lagged response of the climate system, despite the very slow change in $\mathrm{CO}_{2}$ concentration that we apply. This suggests that the change of the atmospheric $\mathrm{CO}_{2}$ concentration in our experiments is not slow enough to ensure the maintenance of a quasi-equilibrium system.

\section{Possibility of hysteresis in Arctic sea ice}

a. Arctic sea ice area

As the atmospheric $\mathrm{CO}_{2}$ concentration increases in CO2_UP, the Arctic summer sea ice area decreases continuously; sea ice disappears completely as the $\mathrm{CO}_{2}$ concentration reaches 620 ppmv (Fig. 3a). Once the $\mathrm{CO}_{2}$ concentration decreases again in CO2_DOWN, the summer sea ice starts to recover after the $\mathrm{CO}_{2}$ concentration is reduced to $400 \mathrm{ppmv}$. As the $\mathrm{CO}_{2}$ concentration again reaches its preindustrial level, the Arctic summer sea ice area is about $3.0 \times 10^{6} \mathrm{~km}^{2}$, which is only half of that in CNTR. For the atmospheric $\mathrm{CO}_{2}$ concentration between 400 and 620 ppmv, we find a summer icecovered state in the $\mathrm{CO}_{2}$ concentration increase trajectory and a summer ice-free state in the $\mathrm{CO}_{2}$ concentration decrease trajectory (Fig. 3a), suggestive of multiple equilibria of Arctic summer sea ice cover in response to the atmospheric $\mathrm{CO}_{2}$ forcing. However, with the $\mathrm{CO}_{2}$ concentration fixed at $490 \mathrm{ppmv}$, the summer sea ice in the simulation with increasing $\mathrm{CO}_{2}$ concentration eventually disappears to meet the summer ice-free state, which hence is the steady state for this $\mathrm{CO}_{2}$ concentration (Figs. 3a and $4 \mathrm{a}$ ). This result can be interpreted such that the Arctic summer sea ice cover shows quasi-hysteretic behavior in response to $\mathrm{CO}_{2}$ concentration changes on policy-relevant time scales; however, there is no true hysteresis, which would imply two separate steady states at the same $\mathrm{CO}_{2}$ concentration in this model. The quasi-hysteretic behavior only occurs because of a lagged response of the sea ice cover to the change in 


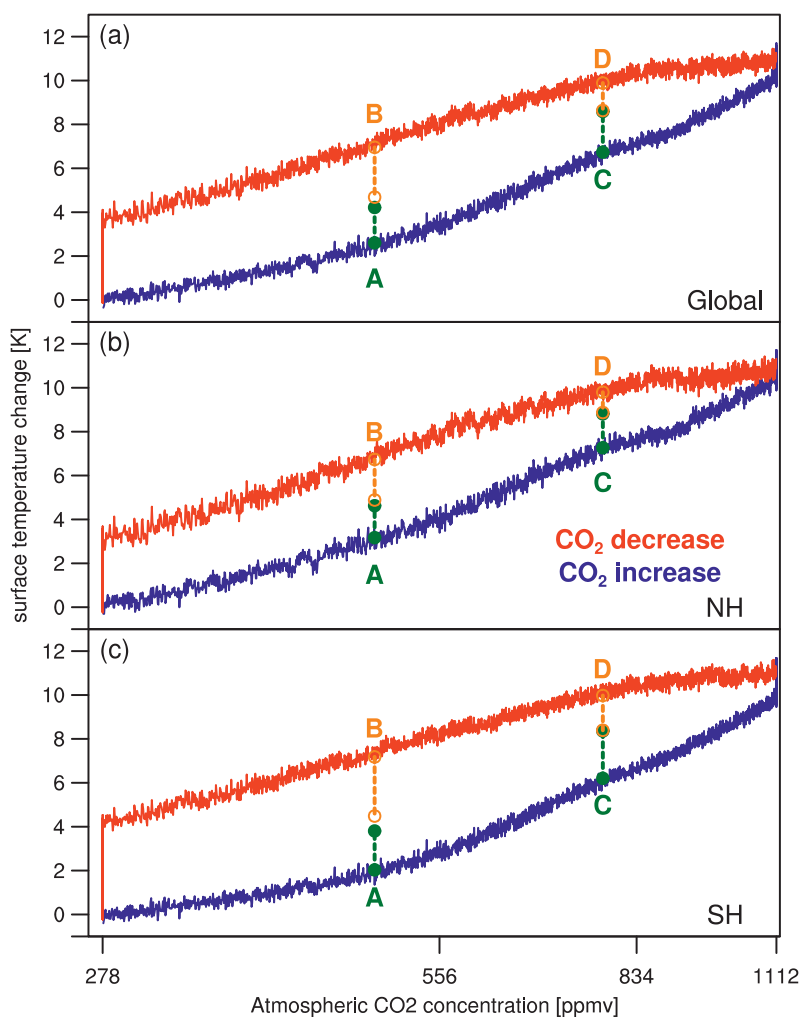

FIG. 2. (a) Global-averaged, (b) NH-averaged, and (c) SHaveraged annual-mean surface temperature anomalies as a function of the atmospheric $\mathrm{CO}_{2}$ concentration in the ECHAM5/MPI-OM simulations. The use of blue, red, dark green, and dark orange is as described in Fig. 1. The evolution of simulations A, B, C, and D are given by two points (initial and final state) that is then averaged by the first 100 years and last 100 years of each experiment. Temperature anomalies are with respect to the CNTR, and $\mathrm{CO}_{2}$ concentration is plotted on a logarithmic scale.

$\mathrm{CO}_{2}$ concentration, caused by some slow adjustment processes in the system.

This nonhysteretic behavior is also underlined by the changes in Arctic sea ice cover as a function of $\mathrm{NH}$ annual-mean surface temperature change. Here, Arctic summer sea ice area recovers for decreasing $\mathrm{CO}_{2}$ concentration along a trajectory that is indistinguishable from that with increasing $\mathrm{CO}_{2}$ concentration (Fig. 5a). From this we can conclude that Arctic sea ice reacts rapidly to surface climate processes, which in turn only slowly adjust to the transient atmospheric $\mathrm{CO}_{2}$ forcing. Before we discuss the dominating impact of the surface climate processes on Arctic sea ice in more detail, we will now turn to the response of Arctic winter sea ice.

Here, in contrast to the smooth summer sea ice decline, we find a rapid transition from a winter ice-covered state to an ice-free state when the $\mathrm{NH}$-averaged annual-mean surface temperature increases by about $8 \mathrm{~K}$ (Fig. $5 \mathrm{~b}$ ) to reach $295.2 \mathrm{~K}\left(22.1^{\circ} \mathrm{C}\right)$, while the local surface temperature

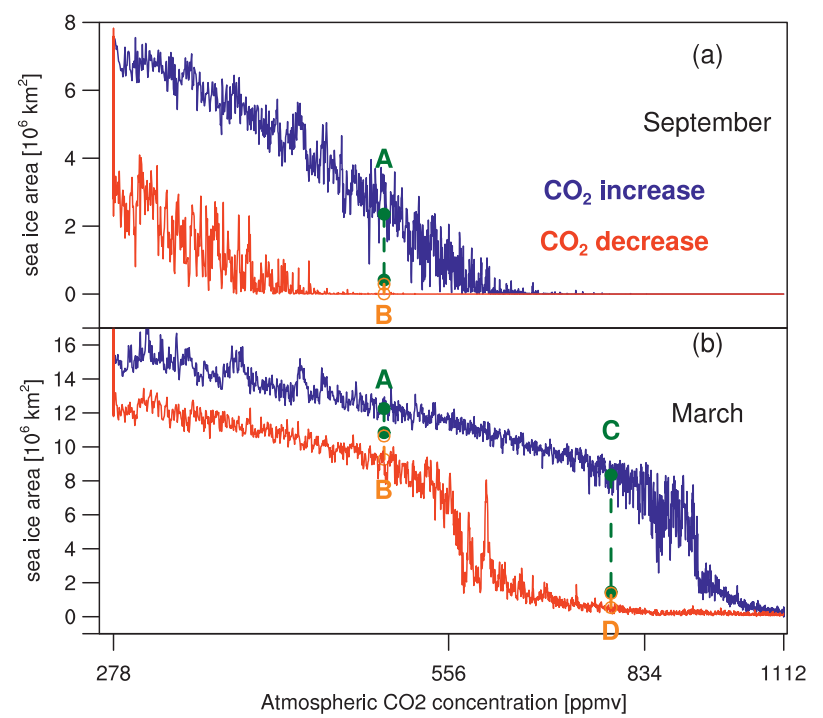

FIG. 3. Arctic sea ice area as a function of the atmospheric $\mathrm{CO}_{2}$ concentration in (a) September and (b) March. The use of blue, red, dark green, and dark orange is as described in Fig. 2. $\mathrm{CO}_{2}$ concentration is plotted on a logarithmic scale.

over the Arctic Ocean suddenly increases by about $4 \mathrm{~K}$ (Fig. 6a). We find a sudden increase of about $5 \mathrm{~W} \mathrm{~m}^{-2}$ in annual-mean absorbed shortwave radiation over the Arctic Ocean domain when the rapid reduction of Arctic winter sea ice area occurs (Fig. 6b). This result is similar to that of Winton (2006), who found an abrupt

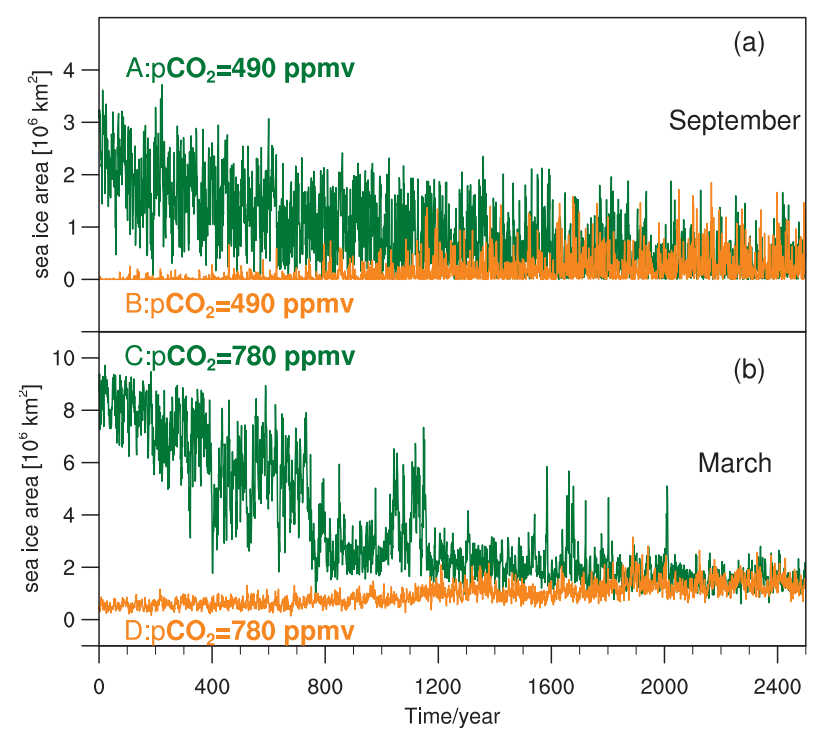

FIG. 4. Time series of Arctic sea ice area (a) in September with keeping the atmospheric $\mathrm{CO}_{2}$ concentration fixed at 490 ppmv, and (b) in March with keeping the atmospheric $\mathrm{CO}_{2}$ concentration fixed at 780 ppmv. The dark green represents experiments started from CO2_UP. The dark orange represents experiments started from CO2_DOWN. 


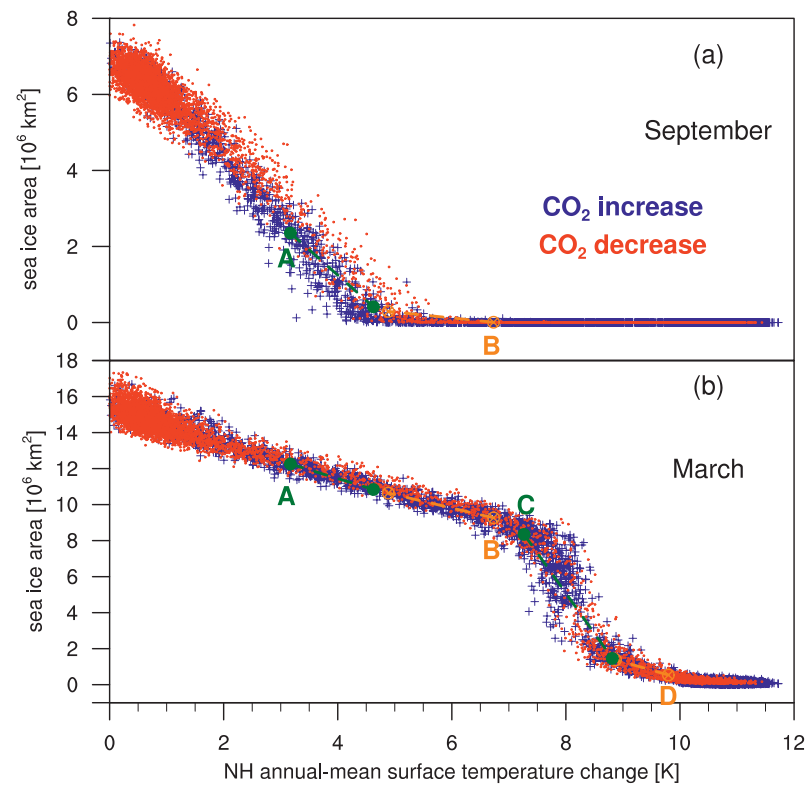

FIG. 5. Arctic sea ice area as a function of $\mathrm{NH}$-averaged annualmean surface temperature change in (a) September and (b) March. The use of blue, red, dark green, and dark orange is as described in Fig. 2. All surface temperature changes are given relative to the simulated CNTR NH annual-mean surface temperature of $287.2 \mathrm{~K}$ $\left(14 \cdot 1^{\circ} \mathrm{C}\right)$.

loss of Arctic winter sea ice in ECHAM5 driven by an enhanced ice-albedo feedback. However, in addition to this sharply enhanced ice-albedo feedback, we also find a sudden increase in the convective precipitation over the Arctic Ocean domain in March, while the rapid loss of Arctic winter sea ice area happens (Fig. 6c). This suggests that atmospheric convection is suddenly triggered by the increased heat and moisture fluxes from the ocean surface once the $\mathrm{NH}$-averaged annual-mean surface temperature increases by about $8 \mathrm{~K}$. Abbot and Tziperman (2008) suggested that this atmospheric convection produces optically thick convective clouds and increases high-latitude moisture levels, both of which trap outgoing longwave radiation and therefore result in further warming and sea ice loss. This sudden onset of atmospheric convective-cloud feedback, as estimated here from convective precipitation, very likely contributes to a sudden increase of the cloud-longwave radiative forcing by about $5 \mathrm{~W} \mathrm{~m}^{-2}$ (Fig. 6b). The wintertime loss of heat from Arctic Ocean to space hence becomes less efficient. This atmospheric convective-cloud feedback might play an essential role for trapping heat in the Arctic Ocean and thus for eliminating of the Arctic winter sea ice cover. This would be consistent with the mechanism suggested by Abbot and Tziperman (2008). Unfortunately, the data we have available from our simulations do not allow us to strictly confirm or reject their hypothesis. This would only

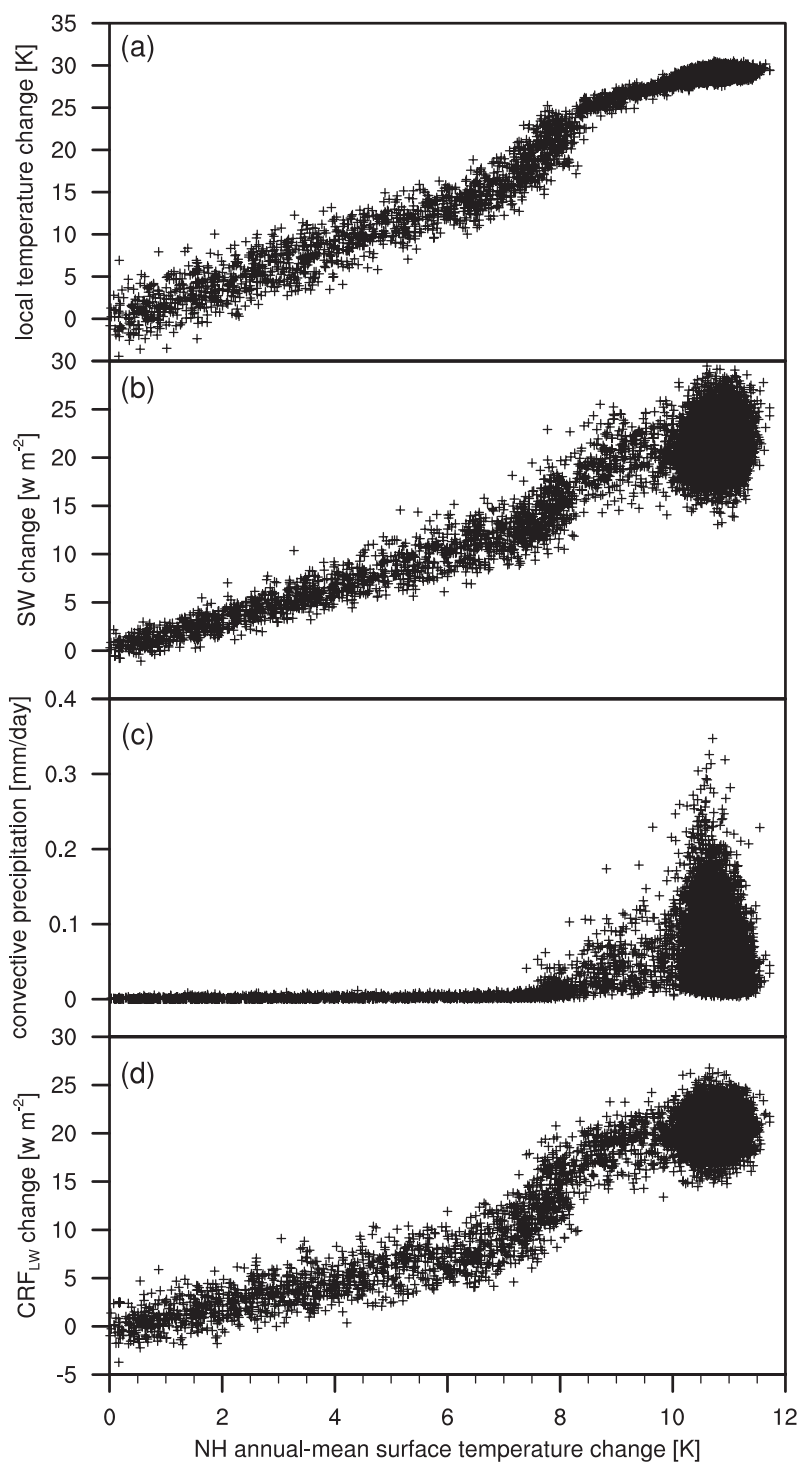

FIG. 6. (a) Local surface temperature change in March, (b) annual-mean absorbed shortwave radiation change at the top of the atmosphere, (c) convective precipitation in March, and (d) cloud longwave-radiative forcing $\left(\mathrm{CRF}_{\mathrm{LW}}\right)$ change at the top of the atmosphere in March averaged over the Arctic Ocean Basin as a function of $\mathrm{NH}$ annual-mean surface temperature change. The radiative fluxes and surface temperature change are with respect to the CNTR. The NH annual-mean surface temperature changes are given relative to that in CNTR of $287.2 \mathrm{~K}\left(14.1^{\circ} \mathrm{C}\right)$. The local surface temperature change over the Arctic Ocean Basin is given relative to that in $\mathrm{CNTR}$ of $244.3 \mathrm{~K}\left(-28.9^{\circ} \mathrm{C}\right)$.

be possible with dedicated experiments with modified physics.

We can exclude the geometric effect as suggested by Eisenman (2010) as a main driver of this rapid reduction in sea ice area, since the sea ice retreats most rapidly in the central Arctic Ocean where it is unbounded by landmasses. This is different from the findings of Armour et al. 
(2011), who found an acceleration of winter sea ice to be caused by geometric effects in their experiments.

As the atmospheric $\mathrm{CO}_{2}$ concentration is reduced in CO2_DOWN to about $650 \mathrm{ppmv}$, the winter sea ice area rapidly recovers to about $8 \times 10^{6} \mathrm{~km}^{2}$, which is approximately equal to the area of the Arctic Ocean Basin. With the atmospheric $\mathrm{CO}_{2}$ concentration in the range of 650 950 ppmv, we find a winter ice-covered state in $\mathrm{CO} 2$ _UP and a winter ice-free state in CO2_DOWN (Fig. 3b). To verify whether the Arctic winter sea ice cover exhibits multiple equilibria, we examine two additional 2500-year-long simulations in which $\mathrm{CO}_{2}$ concentration is kept fixed at 780 ppmv during both $\mathrm{CO} 2$ _UP and $\mathrm{CO} 2$ DOWN (points $\mathrm{C}$ and $\mathrm{D}$ in Fig. $3 b$ ). We find that in CO2_UP the winter ice-covered state evolves toward the winter ice-free state after 1200 years (Figs. $3 b$ and $4 b$ ). The winter ice-free state in CO2_DOWN is almost stationary over 1500 years. This suggests that the winter ice-free state is the steady state for this $\mathrm{CO}_{2}$ concentration; the winter ice-covered state is only transient. Hence, as for Arctic summer sea ice, the apparent hysteresis behavior shown in Fig. $3 \mathrm{c}$ is not a true hysteresis, but simply a result of the lagged response of the system. This is also apparent from the response of the Arctic winter sea ice as a function of $\mathrm{NH}$-mean surface temperature: Arctic winter sea ice recovers with decreasing $\mathrm{CO}_{2}$ concentration along a trajectory that is indistinguishable from that with increasing $\mathrm{CO}_{2}$ concentration (Fig. 5b). Both in the warming and the cooling trajectories, the rapid transition of the winter sea ice cover occurs when the NH-mean surface temperature is about $8 \mathrm{~K}$ higher than in the preindustrial climate.

As we will see later, in the Antarctic there is a clear difference in the sea ice area as a function of surface temperature change between the cooling and the warming trajectories, indicating a less pronounced impact of surface climate processes on the sea ice state there. To examine why surface climate processes are so dominant in defining the sea ice state in the Arctic, we must examine the oceanic near-surface conditions. In the Arctic Ocean, the strong halocline is responsible for maintaining water column stability, thus isolating the surface water and hence the sea ice from the deep water. While we increase the atmospheric $\mathrm{CO}_{2}$ concentration, a warming and freshening of the surface water strengthens the Arctic halocline and inhibits the penetration of heat into the deep ocean (Aagaard et al. 1981; Akitomo 1999). As we decrease the $\mathrm{CO}_{2}$ concentration in $\mathrm{CO} 2$ _DOWN, we find no evidence that the Arctic halocline is destroyed by strong deep convection. The upper and the intermediate water masses remain decoupled, owing to the protection given by the strong halocline. In addition, the thermodynamic forcing is more relevant for the change in
Arctic sea ice coverage, because the sea ice movement there is constrained by the surrounding landmasses (e.g., Eisenman 2010; Notz and Marotzke 2012). Consequently, surface climate processes are the controlling factor (directly or indirectly) for Arctic sea ice coverage. The Arctic sea ice coverage shows a lagged response to atmospheric $\mathrm{CO}_{2}$ concentration, because the adjustment of surface processes lags atmospheric $\mathrm{CO}_{2}$ concentration owing to the ocean's thermal inertia.

The fact that both Arctic summer and winter sea ice covers show no true hysteresis behavior suggests that the evolution of the Arctic ice cover is in principle reversible. However, the Arctic remains ice free for a very long time as we decrease the atmospheric $\mathrm{CO}_{2}$ concentration. The Arctic summer and winter ice-free states in the $\mathrm{CO}_{2}$ DOWN are steady states; in contrast, the Arctic summer and winter ice-covered states in CO2_UP are only transient at a certain atmospheric $\mathrm{CO}_{2}$ concentration range. As we will discuss next, some slow adjustment processes eliminate the Arctic sea ice cover already at relatively low atmospheric $\mathrm{CO}_{2}$ concentration. Hence, the Arctic sea ice state as simulated by, for example, the transient simulations of CMIP3 and CMIP5 is higher, and often significantly higher, than the amount of Arctic sea ice that can exist at any given $\mathrm{CO}_{2}$ concentration at equilibrium.

\section{b. Mechanism of the lagged response in the Arctic sea ice decline}

In our experiments, we quadruple the atmospheric $\mathrm{CO}_{2}$ concentration over 2000 years, but the reduction of Arctic summer and winter sea ice area still shows a lagged response. Which slow climatic adjustment eliminates the Arctic sea ice cover as we keep the $\mathrm{CO}_{2}$ concentration fixed at 490 and 780 ppmv? To answer this question, we examine the changes in the annual cycles of sea ice volume and heat flux over the Arctic Ocean domain of experiment $\mathrm{A}\left(p_{\mathrm{CO} 2}=490 \mathrm{ppmv}\right)$ and experiment $\mathrm{C}\left(p_{\mathrm{CO} 2}=780 \mathrm{ppmv}\right)$. For changes in the heat flux, we consider five terms: the net shortwave radiative flux difference (i.e., the last 100-yr mean minus the first 100-yr mean) at the top of the atmosphere $\Delta F_{\mathrm{SW}}$, the cloud-longwave radiative forcing difference $\triangle \mathrm{CRF}_{\mathrm{LW}}$, which is the difference between full-sky net longwave radiative flux and the clear-sky net longwave radiative flux at the top of the atmosphere, the atmospheric heat transport difference $\Delta F_{A}$, the net surface heat flux difference $\Delta F_{\mathrm{SF}}$, and the oceanic heat transport difference $\Delta F_{O}$. We define the Arctic Ocean domain to be bounded by the Bering Strait, the Fram Strait, and by the shortest connection from Spitsbergen to the northern end of Novaya Zemlya continued to the Siberian coast. The resulting area of the Arctic Ocean is $8.4 \times 10^{6} \mathrm{~km}^{2}$. 

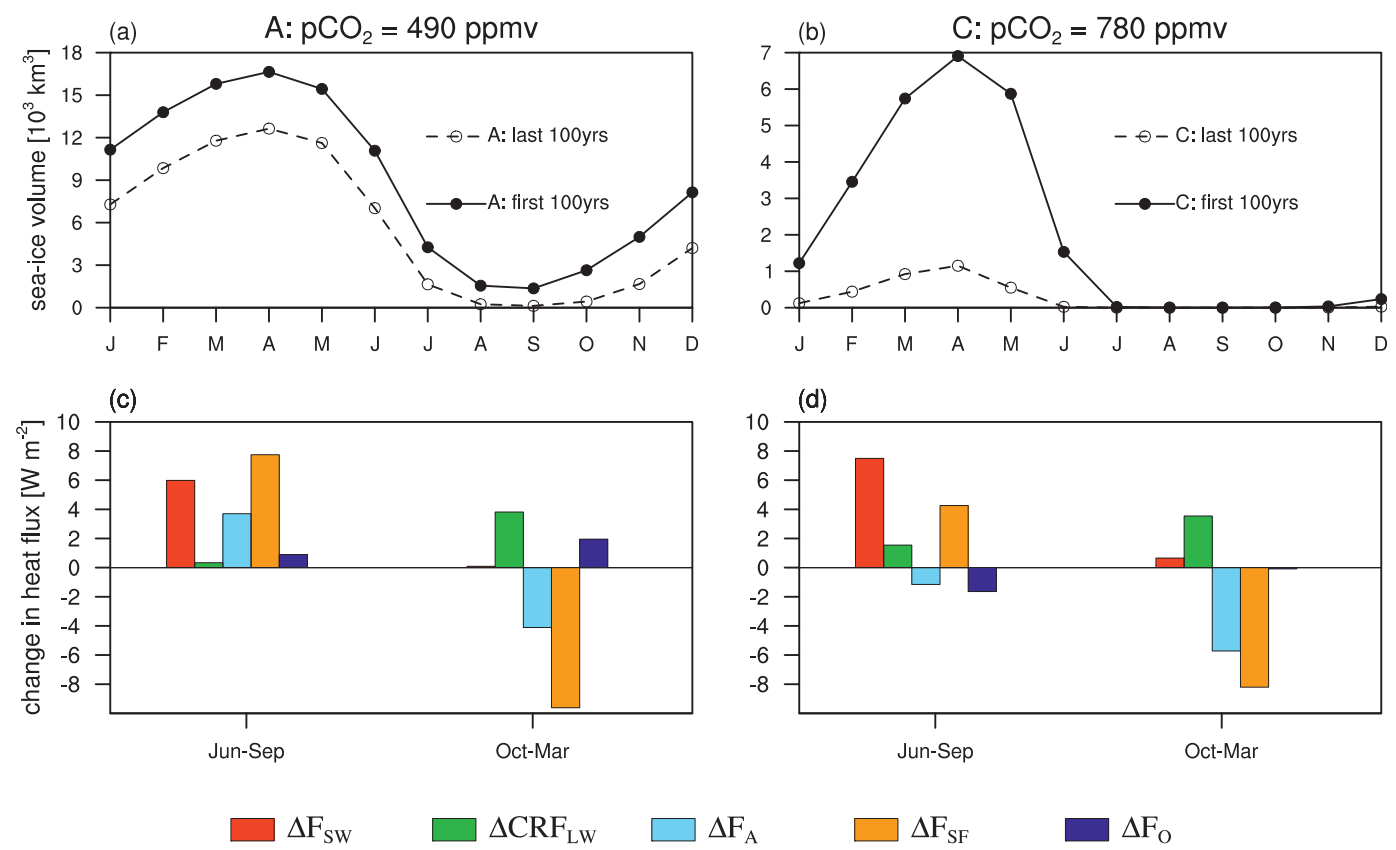

FIG. 7. (a),(b) Mean annual cycle of Arctic sea ice volume and (c),(d) mean energy budget anomalies for the Arctic Ocean domain, from (left) experiment $\mathrm{A}\left(p_{\mathrm{CO} 2}=490 \mathrm{ppmv}\right)$ and (right) experiment $\mathrm{C}\left(p_{\mathrm{CO} 2}=780 \mathrm{ppmv}\right)$. The solid line in (a) and (b) represents the first 100-yr mean, and the dashed line represents the last 100-yr mean of each experiment. In (c) and (d), $\Delta F_{\mathrm{SW}}$ (red) is accumulated shortwave radiative flux difference at the top of the atmosphere, $\Delta \mathrm{CRF}_{\mathrm{LW}}$ (green) is accumulated cloud-longwave radiative forcing difference at the top of the atmosphere, $\Delta F_{A}$ (light blue) is the accumulated atmospheric heat transport difference, $\Delta F_{\mathrm{SF}}$ (orange) is accumulated net surface heat flux difference, and $\Delta F_{O}$ (dark blue) is the accumulated oceanic heat transport difference. The difference represents the last 100-yr mean minus the first 100-yr mean of each experiment. The positive sign in (c),(d) means the downward heat flux.

In experiment $\mathrm{A}$, where we keep the atmospheric $\mathrm{CO}_{2}$ concentration at 490 ppmv for 2500 years, the sea ice volume decreases in all seasons; the summer sea ice cover eventually disappears (Fig. 7a). The energy budget analysis shows that during summer the shortwave radiation over the Arctic increases due to a positive icealbedo feedback. The atmospheric heat transport increases simultaneously (Fig. 7c). This increased heat flux and heat transport enhances the surface warming, thus promoting the Arctic summer sea ice loss, which allows the Arctic Ocean to absorb more solar radiation (Fig. 7c), increasing the heat storage of the Arctic Ocean. In the following autumn and winter, the Arctic Ocean releases more heat to the atmosphere (Fig. 7c), which cools the surface and promotes winter sea ice formation. Concurrently, the cloud cover over the Arctic traps more outgoing longwave radiation because the surface warming emits more outgoing longwave radiation (Fig. 7c), causing a positive cloud-longwave radiative effect. This positive cloud-longwave radiative effect hinders heat loss from the Arctic Ocean and slows down the sea ice formation in winter. This, in turn, further promotes the summer sea ice loss in the following year.
In experiment $\mathrm{C}$, where we keep the atmospheric $\mathrm{CO}_{2}$ concentration at 780 ppmv for 2500 years, the Arctic sea ice volume decreases from a maximum of $7 \times 10^{3} \mathrm{~km}^{3}$ in April to less than $1 \times 10^{3} \mathrm{~km}^{3}$ in all seasons (Fig. $7 \mathrm{~b}$ ). Here, the ice-albedo feedback is not active in late summer because the Arctic is ice free from July to November in this experiment. However, the shortwave radiative flux increases by about $10 \mathrm{~W} \mathrm{~m}^{-2}$ due to the ice-albedo feedback in late spring and early summer when the Arctic is still ice covered (Fig. 7d). This increased shortwave radiative flux allows the Arctic Ocean to gain more heat in spring and summer (Fig. 7d), increasing the heat storage of the Arctic Ocean. This result is similar to that of Winton (2006), who found that the absorbed shortwave radiation sharply increased by about $10 \mathrm{~W} \mathrm{~m}^{-2}$ after the rapid loss of Arctic winter sea ice. The drop in albedo is, hence, important for keeping the Arctic ice free. In contrast to Winton (2006), we find additionally that the Arctic Ocean releases more heat to the atmosphere in winter, which cools the surface water and could promote sea ice formation. Such sea ice formation is, however, hindered by a positive cloud-longwave radiative effect, that limits surface cooling in winter (Fig. 7d). Different 
from experiment $\mathrm{A}$, the positive cloud-longwave radiative effect in experiment $\mathrm{C}$ is caused not only by increasing outgoing longwave radiation, but also by the formation of convective clouds that trap more outgoing longwave radiation (Figs. 6c,d). This positive effect is essential for trapping heat in the Arctic Ocean and thus to eliminate the Arctic winter sea ice cover. Without such an effect, it would be very difficult for the Arctic Ocean to carry the extra heat absorbed in summer throughout winter. We find no significant changes of oceanic heat transport in either experiment $\mathrm{A}$ or $\mathrm{C}$, which suggests that the oceanic heat transport plays a minor role in reducing the sea ice with constant $\mathrm{CO}_{2}$ forcing. A decreased atmospheric heat transport into the Arctic region is probably caused by the stronger warming of the atmosphere over the Arctic relative to lower latitudes (Fig. 7d).

Although the ice-albedo feedback is only active during the sunlit periods, the impact of the corresponding shortwave radiative flux change can extend into the winter sea ice cover, since the Arctic Ocean stores heat during sunlit periods and releases heat during autumn and winter. The ability of the Arctic Ocean to store the excess heat over the course of winter is the key determinant for the evolution and stability of the Arctic sea ice cover (Serreze and Francis 2006; Tietsche et al. 2011). However, the warming of the Arctic Ocean is a slow process, because increased heat loss in winter makes it difficult for the Arctic Ocean to carry the extra heat absorbed in summer through winter so as to perpetuate the feedback (Tietsche et al. 2011). Hence, the reduction of Arctic summer and winter sea ice cover can be strongly delayed by the slowness of the Arctic Ocean warming.

\section{Possibility of hysteresis in Antarctic sea ice}

The Antarctic sea ice cover behaves very differently from the Arctic sea ice cover in response to the atmospheric $\mathrm{CO}_{2}$ forcing. Both the Antarctic summer and winter sea ice area decrease continuously during the warming in $\mathrm{CO} 2$ _UP (Figs. 8a,b); we do not find any rapid transition. Compared to the Arctic Ocean, the Antarctic needs longer time and also needs higher atmospheric $\mathrm{CO}_{2}$ concentration to become ice free. The Antarctic reaches the summer ice-free state after almost 1200 model years when the atmospheric $\mathrm{CO}_{2}$ concentration is increased to $770 \mathrm{ppmv}$ in CO2_UP; it reaches the winter ice-free state after almost 2000 years when the atmospheric $\mathrm{CO}_{2}$ concentration is increased to $1112 \mathrm{ppmv}$ in $\mathrm{CO} 2$ _UP. The Antarctic remains ice free even if the atmospheric $\mathrm{CO}_{2}$ concentration is reduced to the preindustrial level at the end of CO2_DOWN. With the atmospheric $\mathrm{CO}_{2}$ concentration kept at 278 ppmv for several millennia in CO2_LOW, the Antarctic sea ice

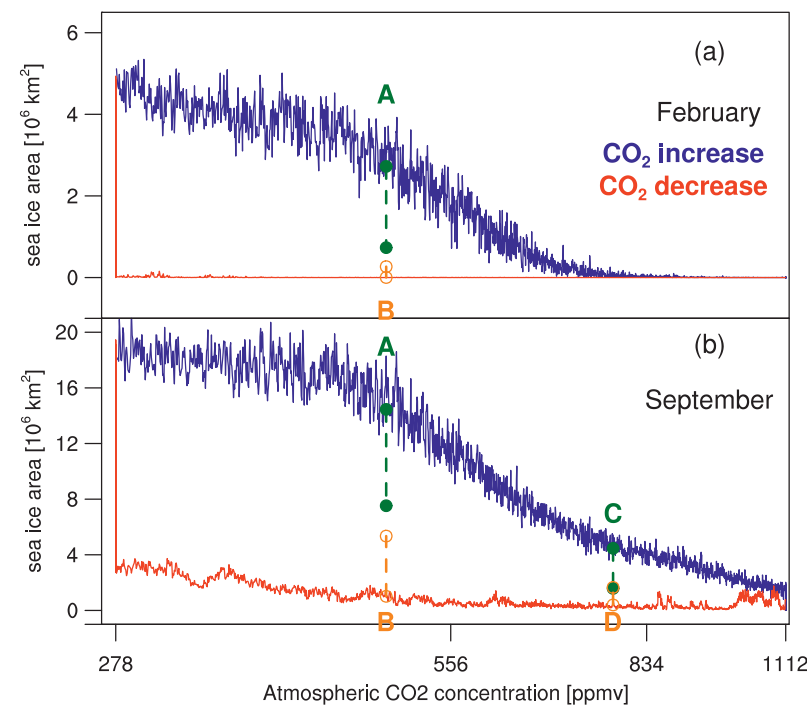

FIG. 8. Antarctic sea ice area as a function of the atmospheric $\mathrm{CO}_{2}$ concentration in (a) February and (b) September. The use of blue, red, dark green, and dark orange is as described in Fig. 2. The $\mathrm{CO}_{2}$ concentration is plotted on a logarithmic scale.

cover recovers slowly to the preindustrial level. In contrast to Arctic sea ice, the Antarctic sea ice coverage recovers along a different trajectory as a function of hemispheric annual-mean surface temperature change for increasing $\mathrm{CO}_{2}$ versus decreasing $\mathrm{CO}_{2}$ concentration (Figs. 9a,b). This suggests the possibility of multiple equilibria of Antarctic sea ice cover in response to the atmospheric $\mathrm{CO}_{2}$ forcing. This result is similar to that of Ridley et al. (2012), who kept atmospheric $\mathrm{CO}_{2}$ concentration constant at quadrupling for 1000 years. Armour et al. (2011) found instead a similar trajectory during $\mathrm{CO}_{2}$ increase and decrease, because in their experiments the atmospheric $\mathrm{CO}_{2}$ concentration is ramped up too fast to give the Antarctic Ocean sufficient time to respond.

In experiments $\mathrm{A}$ and $\mathrm{B}$, the Antarctic summer sea ice cover almost disappears to meet the summer ice-free state, which hence is the steady state for this $\mathrm{CO}_{2}$ concentration (Figs. 8a and 10b). The Antarctic winter sea ice areas from experiments A and B also almost meet, as they do in experiments C and D (Figs. 8b and 10a,c). This suggests that the Antarctic sea ice covered state in the $\mathrm{CO}_{2}$ increase trajectory is still transient. Similar to the Arctic sea ice area, the reduction of the Antarctic sea ice is delayed in its response to the increase of the atmospheric $\mathrm{CO}_{2}$ concentration. In experiment $\mathrm{C}$, the Antarctic winter sea ice area is decreasing; winter sea ice area in experiment $\mathrm{D}$ shows very strong century-timescale variability starting after 700 years of integration (Fig. 10c). Hence, similar to the Arctic sea ice, the Antarctic winter and summer sea ice covers show no true 


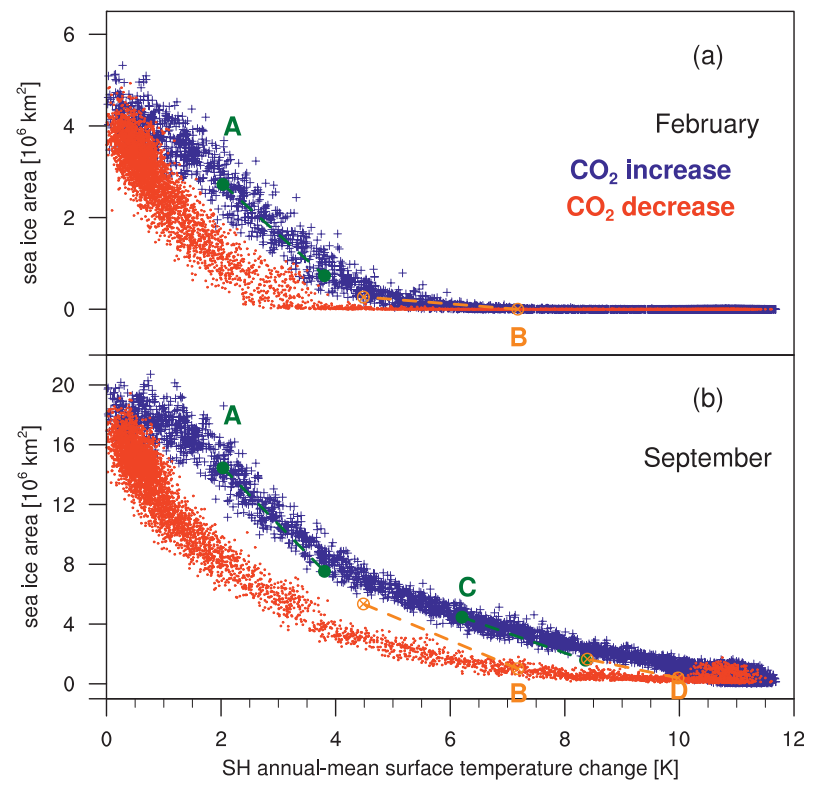

FIG. 9. Antarctic sea ice area as a function of SH-averaged annual-mean surface temperature change in (a) February and (b) September. The use of blue, red, dark green, and dark orange is as described in Fig. 2. All surface temperature changes are given relative to the simulated CNTR SH annual-mean surface temperature of $286.2 \mathrm{~K}\left(13.0^{\circ} \mathrm{C}\right)$.

hysteresis behavior in response to changing atmospheric $\mathrm{CO}_{2}$ concentration, but both the Antarctic winter and summer sea ice covers show a quasi-hysteretic behavior on policy-relevant time scales.

The lagged response in the Antarctic sea ice cover relative to $\mathrm{SH}$ surface temperature change is related to oceanic stratification. Different from the Arctic Ocean, the Antarctic Ocean does not have a strong halocline. Therefore, open-ocean deep convection around Antarctica can easily be triggered by a small change in surface density (Akitomo 1999; McPhee 2003). During the $\mathrm{CO}_{2}$ concentration increase in $\mathrm{CO} 2$ _UP, the ocean surface is heated, which makes the water column more stable. Hence, oceanic convection and other vertical mixing processes become less frequent and less intense (Figs. 11a,c). The intermediate water of the Antarctic Ocean takes up heat throughout the whole period of the atmospheric $\mathrm{CO}_{2}$ concentration increase and stabilization. However, in the $\mathrm{CO}_{2}$ concentration decrease period in CO2_DOWN, the ocean surface is cooled, which destabilizes the water column, and frequent ocean deep convection in the Antarctic Ocean is triggered (Figs. 11b,d). Heat from intermediate water masses becomes entrained into the upper ocean, resulting in a higher ocean surface temperature in wintertime, thus preventing sea ice formation. Hence, it is the strong ocean deep convection that maintains an ice-free Antarctic

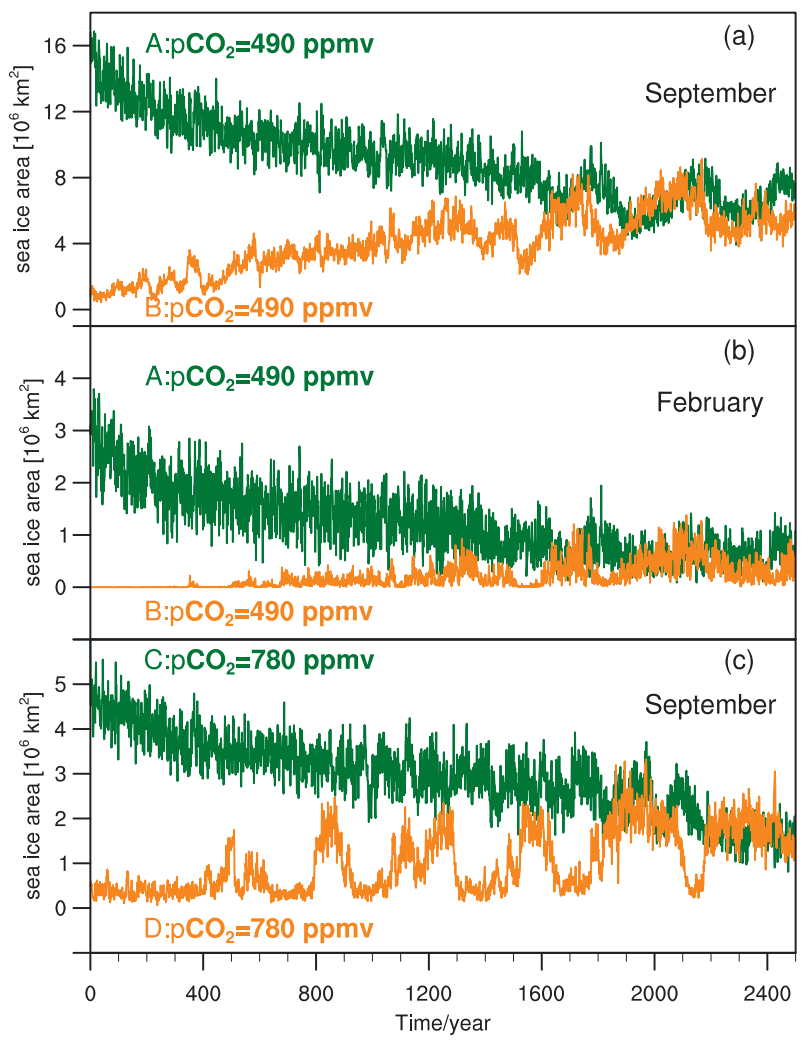

FIG. 10. Time series of Antarctic sea ice area (a) in September and (b) in February with keeping the atmospheric $\mathrm{CO}_{2}$ concentration fixed at 490 ppmv, and (c) in September with keeping the atmospheric $\mathrm{CO}_{2}$ concentration fixed at 780 ppmv. The dark green represents experiments starting from $\mathrm{CO} 2$ _UP. The dark orange represents experiments starting from $\mathrm{CO} 2$ _DOWN.

Ocean throughout the $\mathrm{CO}_{2}$ concentration decrease period. And in contrast to the Arctic, Antarctic sea ice dynamics, which are driven by surface wind patterns and currents, play an important role in the overall evolution of sea ice area (e.g., Comiso and Nishio 2008; Stammerjohn et al. 2008; Notz and Marotzke 2012). Therefore, in contrast to the Arctic sea ice, the surface energy budget is not the most significant factor for the change of Antarctic sea ice in a warm climate; ocean deep convection and sea ice dynamics play a more dominant role. This is the reason why the Antarctic sea ice cover shows a much more strongly lagged response to changes in atmospheric $\mathrm{CO}_{2}$ concentration than the Arctic sea ice cover. In contrast to the Arctic sea ice cover, the response of the Antarctic sea ice cover also significantly lags behind surface temperature evolution.

\section{Summary and conclusions}

Using the state-of-the-art AOGCM ECHAM5/MPI-OM, we perform several idealized simulations to investigate 


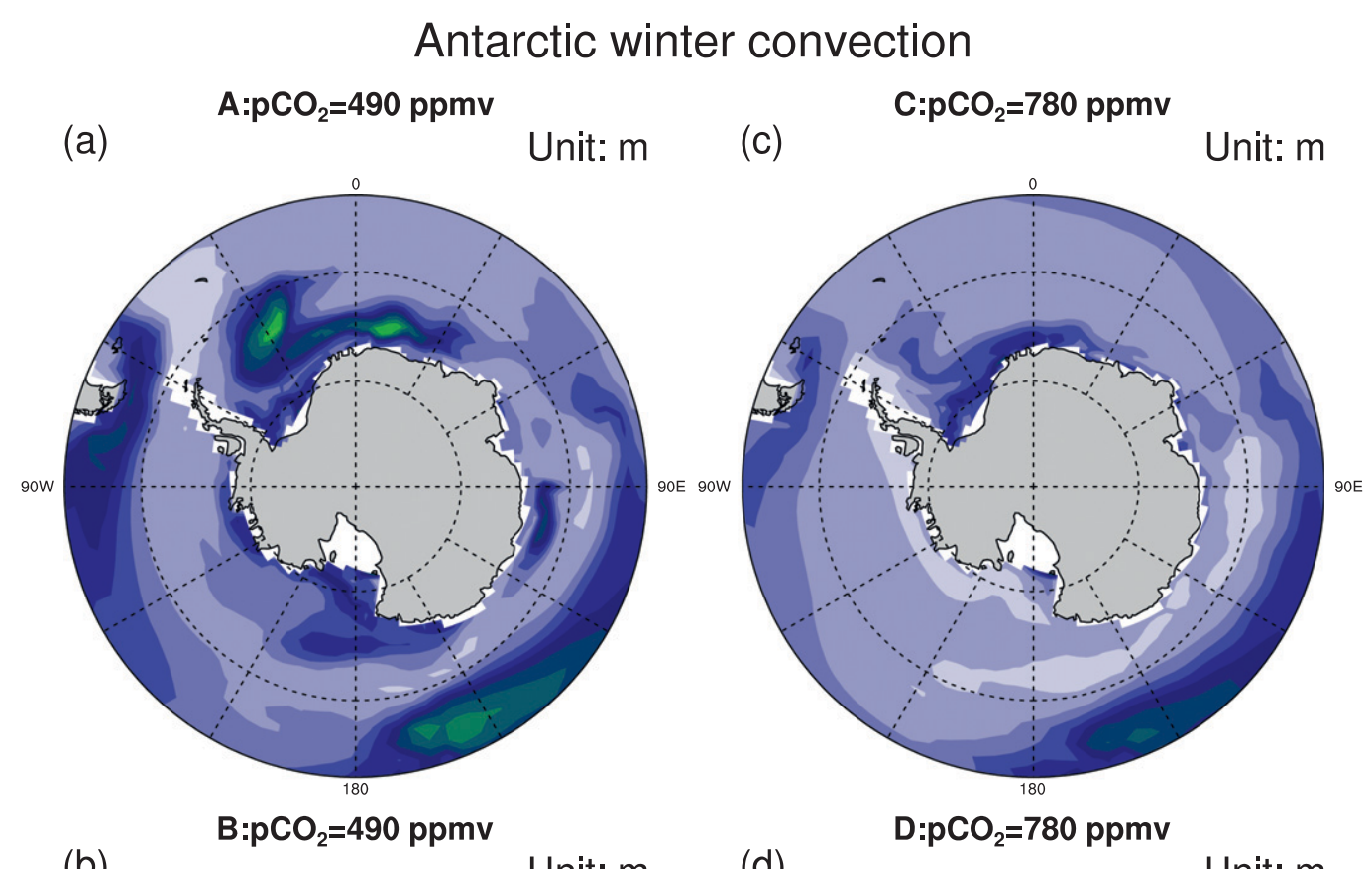

(b)

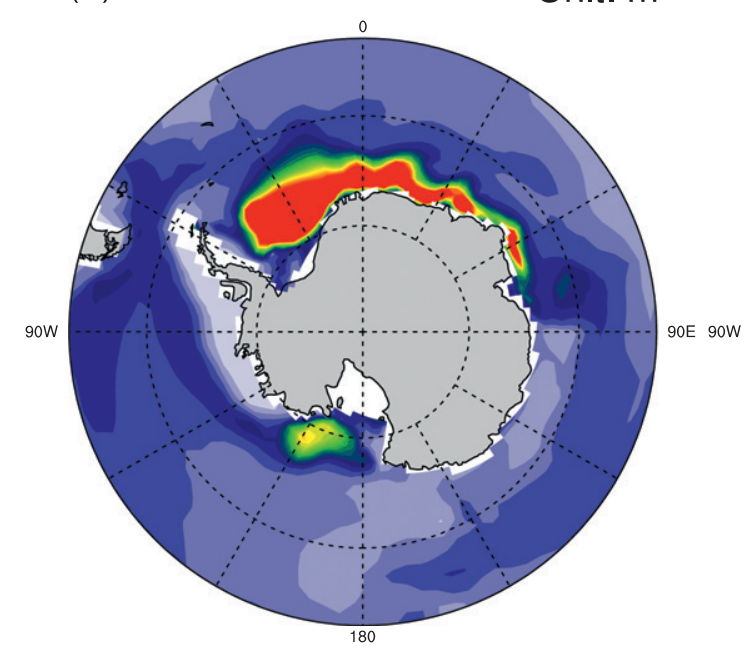

(d)

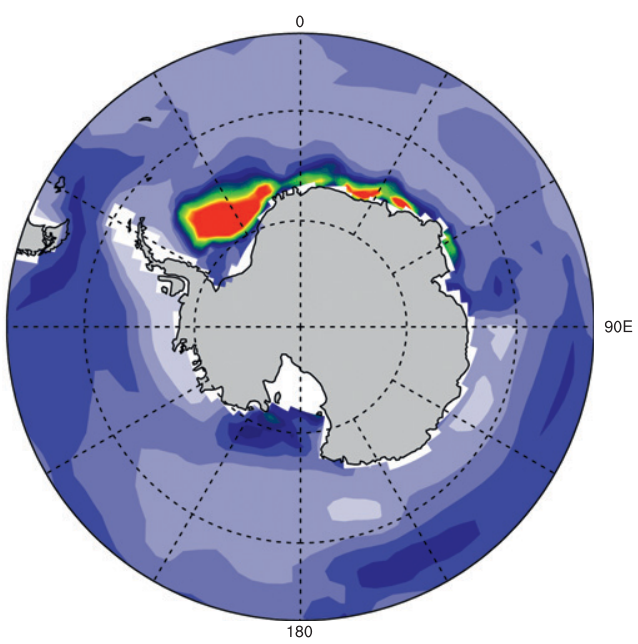

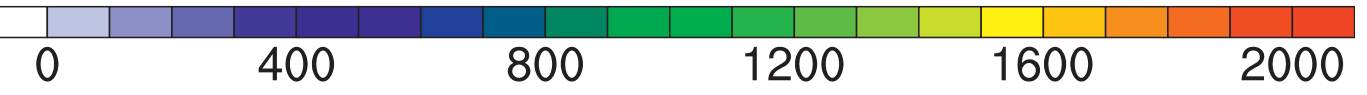

FIG. 11. First 100-yr mean Antarctic Ocean mixed layer thickness in September from experiment (a) A: $p_{\mathrm{CO} 2}=490$ ppmv, (b) B: $p_{\mathrm{CO} 2}=490$ ppmv, (c) C: $p_{\mathrm{CO} 2}=780$ ppmv, and (d) D: $p_{\mathrm{CO} 2}=780$ ppmv.

the hysteresis behavior of Arctic and Antarctic sea ice in response to changing atmospheric $\mathrm{CO}_{2}$ concentration. In contrast to previous studies with a much faster "ramp up and ramp down" of the atmospheric $\mathrm{CO}_{2}$ concentration (Armour et al. 2011; Ridley et al. 2012), we very slowly change the atmospheric $\mathrm{CO}_{2}$ concentration over 2000 years. We investigate the impact of both the fast upper-ocean adjustment and the slow deep-ocean adjustment on the sea ice. The main findings are as follows:
1) We find a rapid transition during the loss of the Arctic winter sea ice cover in a warm climate, once the $\mathrm{NH}$-averaged annual-mean surface temperature has increased by about $8 \mathrm{~K}$. This rapid transition is associated with a sharply enhanced ice-albedo feedback and a sudden onset of strong atmospheric convection, consistent with the mechanism suggested by Abbot and Tziperman (2008). Consistent with previous studies with AOGCMs (Winton 2006, 2008; Tietsche et al. 2011; Armour et al. 2011; Ridley et al. 
2012), we find no evidence of tipping points or rapid transitions during the loss of the Arctic summer sea ice. In contrast to the Arctic winter sea ice loss, the summer sea ice cover retreats linearly with increasing atmospheric $\mathrm{CO}_{2}$ concentration.

2) We find no evidence of multiple equilibria and true hysteresis behavior of Arctic summer or winter sea ice cover in response to changing atmospheric $\mathrm{CO}_{2}$ concentration in ECHAM5/MPI-OM. However, both the Arctic summer and winter sea ice covers show a lagged response to changing atmospheric $\mathrm{CO}_{2}$ concentration, which can be interpreted as a quasihysteretic behavior on policy-relevant time scales. There is no lagged response to the NH surface temperature change. This suggests that the lagged response of the Arctic sea ice cover to changing $\mathrm{CO}_{2}$ concentration is associated with the thermal inertia of the Arctic Ocean. Fixing the atmospheric $\mathrm{CO}_{2}$ concentration at 490 and 780 ppmv for 2500 years, we find a slow ocean warming. A positive cloud-longwave radiative effect, which is caused by the surface warming, hinders heat loss from the Arctic Ocean and slows the sea ice formation in winter, which in turn promotes further summer sea ice loss in the following year. The corresponding positive ice-albedo feedback leads to further warming of the Arctic Ocean. Hence, it is the slowness of Arctic Ocean warming that delays the reduction of Arctic summer and winter sea ice cover.

3) The Antarctic sea ice cover retreats continuously without rapid transition during the warming trajectory. Similar to the Arctic sea ice cover, the Antarctic sea ice cover shows no evidence of true hysteresis behavior or multiple equilibria in response to the atmospheric $\mathrm{CO}_{2}$ concentration in ECHAM5/MPIOM. However, the Antarctic summer and winter sea ice covers show a more strongly lagged response to the atmospheric $\mathrm{CO}_{2}$ concentration compared to the Arctic sea ice cover. In contrast to the Arctic sea ice cover, the response of Antarctic winter and summer sea ice covers lag significantly behind the surface temperature change beyond 1000 years.

4) In the Antarctic, the response of the sea ice is greatly delayed because there is no strong halocline. Ocean deep convection can easily be triggered as we decrease the atmospheric $\mathrm{CO}_{2}$ concentration. This causes the Antarctic Ocean to remain ice free for a very long time, and causes changes in Antarctic sea ice to lag behind the surface temperature change.

5) Although we change the $\mathrm{CO}_{2}$ concentration very slowly, the equilibrium area of sea ice in both hemispheres is always below the sea ice area during the simulation with increased $\mathrm{CO}_{2}$ concentration. Hence, the sea ice state as simulated by any transient simulation with increasing $\mathrm{CO}_{2}$ concentration will be higher, often significantly higher, than the amount of sea ice that can exist at any given $\mathrm{CO}_{2}$ concentration at equilibrium. In particular, we find that for a $\mathrm{CO}_{2}$ concentration of $490 \mathrm{ppmv}$, the equilibrium state of the Arctic sea ice is ice free in summer; for a $\mathrm{CO}_{2}$ concentration of $780 \mathrm{ppmv}$, the equilibrium state is ice free year-round. This implies that the sea ice coverage as simulated in transient CMIP3 and CMIP5 simulations provide an upper bound on sea ice coverage after a possible stabilization of $\mathrm{CO}_{2}$ concentration.

Acknowledgments. We thank Helmuth Haak for his assistance in setting up the experiment and for providing the preindustrial control simulation. We thank Thorsten Mauritsen, Malte Heinemann, Dorian Abbot, and an anonymous reviewer for valuable discussions and helpful comments on the manuscript. We thank Hongmei Li, Laura Niederdrenk, and Max Popp for discussions and proofreading. The model simulations were carried out on the supercomputing system of the German Climate Computing Center (DKRZ) in Hamburg, Germany.

\section{REFERENCES}

Aagaard, K., L. K. Coachman, and E. Carmack, 1981: On the halocline of the Arctic Ocean. Deep-Sea Res., 28A, 529-545.

Abbot, D. S., and E. Tziperman, 2008: Sea ice, high-latitude convection, and equable climates. Geophys. Res. Lett., 35, L03702, doi:10.1029/2007GL032286.

Akitomo, K., 1999: Open-ocean deep convection due to thermobaricity: 1. Scaling argument. J. Geophys. Res., 104 (C3), 52255234.

Armour, K., I. Eisenman, E. Blanchard-Wrigglesworth, K. McCusker, and C. M. Bitz, 2011: The reversibility of sea ice loss in a stateof-the-art climate model. Geophys. Res. Lett., 38, L16705, doi:10.1029/2011GL048739.

Budyko, M. I., 1969: The effect of solar radiation variations on the climate of the earth. Tellus, 21, 611-619.

Comiso, J. C., and F. Nishio, 2008: Trends in the sea ice cover using enhanced and compatible AMSR-E, SSM/I, and SMMR data. J. Geophys. Res., 113, C02S07, doi:10.1029/2007JC004257.

Eisenman, I., 2010: Geographic muting of changes in the Arctic sea ice cover. Geophys. Res. Lett., 37, L16501, doi:10.1029/ 2010GL043741.

_ 2012: Factors controlling the bifurcation structure of sea ice retreat. J. Geophys. Res., 117, D01111, doi:10.1029/ 2011JD016164.

— during the loss of Arctic sea ice. Proc. Natl. Acad. Sci. USA, 106, $28-32$.

Hibler, W. D., 1979: A dynamic thermodynamic sea ice model. J. Phys. Oceanogr., 9, 815-846.

Holland, M. M., C. M. Bitz, and B. Tremblay, 2006: Future abrupt reductions in the summer Arctic sea ice. Geophys. Res. Lett., 33, L23503, doi:10.1029/2006GL028024.

,,--- , and D. Bailey, 2008: The role of natural versus forced change in future rapid summer arctic ice loss. Arctic Sea 
Ice Decline: Observations, Projections, Mechanisms, and Implications, Geophys. Monogr., Vol. 180, Amer. Geophys. Union, $133-150$

Jungclaus, J. H., and Coauthors, 2006: Ocean circulation and tropical variability in the coupled model ECHAM5/MPI-OM. J. Climate, 19, 3952-3972.

Li, C., J.-S. von Storch, and J. Marotzke, 2013: Deep-ocean heat uptake and equilibrium climate response. Climate Dyn., 40, 1071-1086.

Lindsay, R. W., and J. Zhang, 2005: The thinning of the Arctic sea ice 1988-2003: Have we passed a tipping point? J. Climate, 18, 4879-4894.

Marsland, S. J., H. Haak, J. H. Jungclaus, M. Latif, and F. Roeske, 2003: The Max-Planck-Institute global ocean/sea ice model with orthogonal curvilinear coordinates. Ocean Modell., 5, 91-127.

McPhee, M. G., 2003: Is thermobaricity a major factor in Southern Ocean ventilation? Antarct. Sci., 15, 153-160.

North, G. R., 1990: Multiple solutions in energy balance climate models. Global Planet. Change, 82, 225-235.

Notz, D., 2009: The future of ice sheets and sea ice: Between reversible retreat and unstoppable loss. Proc. Natl. Acad. Sci. USA, 106, 20 590-20 595.

— , and J. Marotzke, 2012: Observations reveal external driver for Arctic sea-ice retreat. Geophys. Res. Lett., 39, L08502, doi:10.1029/2012GL051094.

— , F. A. Haumann, H. Haak, J. H. Jungclaus, and J. Marotzke, 2013: Arctic sea-ice evolution as modeled by Max Planck Institute for Meteorology's Earth System Model. J. Adv. Model. Earth Syst., doi:10.1002/jame.20016, in press.

Ridley, J. K., J. Lowe, and D. Simonin, 2008: The demise of Arctic sea ice during stabilisation at high greenhouse gas concentrations. Climate Dyn., 30, 333-341.

,-- , and H. T. Hewitt, 2012: How reversible is sea ice loss? Cryosphere Discuss., 6, 193-198.

Roeckner, E., and Coauthors, 2003: The atmospheric general circulation model ECHAM5. Part I: Model description. MaxPlanck-Institut für Meteorologie Rep. 349, 127 pp.
_ , and Coauthors, 2006: Sensitivity of simulated climate to horizontal and vertical resolution in the ECHAM5 atmosphere model. J. Climate, 19, 3771-3791.

Sellers, W. D., 1969: A global climate model based on the energy balance of the earth-atmosphere system. J. Appl. Meteor., 8, 392-400.

Semtner, A. J., 1976: A model for the thermodynamic growth of sea ice in numerical investigations of climate. J. Phys. Oceanogr., 6, 379-389.

Serreze, M. C., and J. A. Francis, 2006: The Arctic amplification debate. Climatic Change, 76, 241-264.

Stammerjohn, S. E., D. G. Martinson, R. C. Smith, X. Yuan, and D. Rind, 2008: Trends in Antarctica annual sea ice retreat and advance and their relation to El Niño-Southern Oscillation and southern annular mode variability. J. Geophys. Res., 113, C03S90, doi:10.1029/2007JC004269.

Stouffer, R. J., 2004: Time scales of climate response.J. Climate, 17, 209-217.

Stroeve, J. C., M. C. Serreze, M. M. Holland, J. E. Kay, J. Malanik, and A. P. Barrett, 2012: The Arctic's rapidly shrinking sea ice cover: A research synthesis. Climatic Change, 110, 1005-1027.

Tietsche, S., D. Notz, J. H. Jungclaus, and J. Marotzke, 2011: Recovery mechanisms of Arctic summer sea ice. Geophys. Res. Lett., 38, L02707, doi:10.1029/2010GL045698.

Valcke, S., D. Caubel, and L. Terray, 2003: OASIS3 Ocean Atmosphere Sea Ice Soil user's guide. CERFACS Tech. Rep. TR/CMGC/03/69, 85 pp.

Vinnikov, K. Y., and Coauthors, 1999: Global warming and Northern Hemisphere sea ice extent. Science, 286, 1934 1937.

Winton, M., 2006: Does the Arctic sea ice have a tipping point? Geophys. Res. Lett., 33, L23504, doi:10.1029/2006GL028017.

_ 2008: Sea ice-albedo feedback and nonlinear Arctic climate change. Arctic Sea Ice Decline: Observations, Projections, Mechanisms, and Implications, Geophys. Monogr., Vol. 180, Amer. Geophys. Union, 111-131. 